\title{
Total Content of Phenolics and Antioxidant Activity in Crispbreads with Plant By-product addition
}

\author{
* Daiga Konrade, Dace Klava \\ Latvia University of Agriculture, Faculty of Food Technology, Rīgas Street 22, Jelgava, LV-3004, Latvia
}

\begin{abstract}
Vegetable processing in food industry results in significant amount of by-products - peel, mark, bark, seeds still rich in bioactive compounds. Apple, carrot and pumpkin peel and mark may be used for production of crispbreads as functional ingredients. The objective of this study is to investigate the stability of total phenolic content (TPC) and antioxidant activity after high temperature and short time (HTST) extrusion cooking of a wheat and rice- based crispbreads with addition of apple, carrot and pumpkin by-products obtained after juice extraxtion and dried. Raw materials for crispbread production were wheat flour, rice flour, wheat bran $(72 \%, 24 \%$ and $4 \%$ respectively) with addition of microwave-vacuum dried by-product powder in different amount $(5 \%, 10 \%, 15 \%, 20 \%)$. Extrusion process was performed by using a laboratory singlescrew extruder GÖTTFERT 1 screw Extrusiometer L series (Germany). Total phenolic content (TPC) was determined using the Folin Ciocalteu method. Antioxidant activity was evaluated by free radical 2, 2-diphenyl1-picrylhydrazyl (DPPH) antioxidant scavenging activity using a modified colorimetric method. Comparing different raw formulations, it was observed that the TPC of the apple by-product flour was significantly higher $(\mathrm{p}<0.05)$ than in carrot and pumpkin flour. TPC in cereal-based crispbread was $36.06 \pm 1.15$ before extrusion and $13.90 \pm 1.01 \mathrm{mg}$ GAEg-1 DW (milligram Gallic acid equivalent per $100 \mathrm{~g}$ of dry weight (mg GAE 100 $\mathrm{g}^{-1} \mathrm{DW}$ ) after extrusion. Addition of apple BPF increased TPC in crispbreads to $106.25 \pm 2.08$, carrot BPF $84.73 \pm 3.45$ and pumpkin BPF to $108.82 \pm 1.04 \mathrm{mg} \mathrm{GAEg}^{-1} \mathrm{DW}$. Antioxidant activity of control sample was $1.07 \pm 0.01 \mathrm{mg}$ TE (Trolox equivalents) $\mathrm{g}^{-1} \mathrm{DW}$ but in samples with addition of $20 \%$ apple by- products, it reached $3.77 \pm 0.02 \mathrm{TE} \mathrm{g}^{-1} \mathrm{DW}$ for samples wih $20 \%$ carrot by- products reached $2.52 \pm 0.03 \mathrm{TE} \mathrm{g}^{-1} \mathrm{DW}$ and for samples wih $20 \%$ pumpkin by- products reached $3.77 \pm 0.02 \mathrm{TE} \mathrm{g}^{-1} \mathrm{DW}$.
\end{abstract}

Keywords: antioxidants, by-products, crispbreads, extrusion, phenolics.

\section{Introduction}

The food industry generates high amount of byproducts from a variety of sources and the waste management is one of the major parts of food industries. Around 100 million tonnes of food are wasted annually in the EU. If nothing is done, food waste could rise to over 120 million tonnes by 2020 . Global quantitative food losses and waste per year are roughly $30 \%$ for cereals; $40-50 \%$ for root crops, fruits and vegetables. About $38 \%$ of food wastes occur during food processing (Rizui, 2015).

Production of juice from apple, carrots and pumpkin result in such by-products as bark, mark, peel, seeds which are still rich in bioactive compounds (Figuerola \& Mar, 2005; Nayak et al., 2011). Vegetables are one of major antioxidants sources. Antioxidants are compounds that inhibit or delay the oxidation of other molecules by inhibiting the initiation or propagation of oxidizing chain reactions. They can be synthetic or natural (Eskicioglu, Kamiloglu, \& Nilufer-erdil, 2015). Several scientific evidences have shown adverse effects of synthetic antioxidants. Antioxidants act as inactivates for free radicals. Most common antioxidants in vegetables and spices are vitamin C, E, phenolic compounds, carotenoids (Haminiuk et al., 2012). They are compounds when added to food products can increase the shelf-life of food products during processing. In particular, phenolic compounds isolated from plants are recognised as the most promising group of molecules that help to prevent oxidation and maintain product quality (Olfe, Ianzhong, \& Iu, 2003).

\footnotetext{
* Corresponding Author's email: daigakonrade@gmail.com
} 
The apple (Malus domestico) pomace of the high carbohydrate content is used as a substrate in a number of microbial processes for the production of organic acids, enzymes, and pigments (Figuerola \& Mar, 2005). Apple pomace can be used for flavour compounds, oxalic acid and as a medium for bakers yeast for pigment production, radical-scavenging and antioxidant properties of apple polyphenols are frequently cited as important contributors in different models of human chronic diseases (Elleuch et al., 2011; Haminiuk et al., 2012).

The carrot (Daucus carota) pomace is a byproduct obtained during carrot juice processing. It is rich source of $\beta$-carotene and contains other vitamins like thiamine, riboflavin and minerals. The juice yield in carrots is only $60-70 \%$, and even up to $80 \%$ of carotene may be lost with left over carrot pomace. The consumption of carrot is increasing steadily due to its recognition as an important source of natural antioxidants with anticancer activity. Carrot is a significant source of phytochemicals, including phenolics and carotenoids. Due to their appreciable level of different compounds, carrots are considered a functional food with significant health promoting properties (Arscott \& Tanumihardjo, 2010).

Pumpkin (Cucurbita pepo) peel is rich in pectin and used as a gelling agent and thickening agent, as well as acts as a stabilizer in food (Rakcejeva et al., 2011; Aziah \& Komathi, 2009). Pumpkin flesh is an excellent source of $\beta$-carotene, which the body converts into the important antioxidant of vitamin A. It contains a number of biologically active components such as polysaccharides, proteins and peptides, phenolic compounds, terpenoids and sterols. Pumpkins are particularly interesting since they are rich source of fibre and bioactive substances like carotenoids and polyphenols. Besides the provitamin A activity of some carotenoids such as b carotene and a-carotene, studies have also indicated that the consumption of carotenoids lowers the risk of degenerative and cardiovascular diseases, cataracts, and certain types of carcinomas (Provesi, Dias, \& Amante, 2011).

Pumpkin seeds are rich in carotenoids, including lutein, $\alpha$-carotene, and $\beta$-carotene. The seed oil is rich in unsaturated fatty acids, including linoleic, oleic acids. The oil is also rich in vitamin $\mathrm{E}$, including both gamma-tocopherol and alpha-tocopherol. It has been as raw material for development of functional food (Sojak, Jaros, \& Głowacki, 2014). Only several studies are dealing with the influence of the extrusion on carotenoids, primarily b-carotene (Emin, MayerMiebach, \& Schuchmann, 2012; Waramboi, Gidley, \& Sopade, 2013) and lycopene (Dutta et al., 2006)
Food processing waste has a potential to be converted into useful products and utilized as source of the functional ingredient for development of products with high nutritional value. One of methods is extrusion processing due to its versatility, high productivity, relative low cost, energy efficiency (Huber, 2001; Emin, Mayer-Miebach, \& Schuchmann, 2012).

Extrusion is a high-temperature, short-time (HTST) process and combines several unit operations - mixing, melting, kneading which can be manipulated to provide desired product and starchy food materials are plasticised, cooked and in some cases puffed/ expanded by a combination of moisture, pressure, heating and mechanical shear. For production of extruded food products grain is used as it contains starch and protein complexes. To obtain appeelness and texture of final product several flours are mixed and by products are added (Sarawong et al., 2014). Our purpose of study is to make products from cereal based matrix with addition of food processing by products.

The objective of this study is to investigate the stability of total phenolic content (TPC) and antioxidant activity after high temperature and short time (HTST) extrusion cooking of a wheat and ricebased crispbreads with addition of apple, carrot and pumpkin by-products obtained after juice extraxtion and dried.

\section{Materials and Methods}

The study was realised in the scientific laboratories of the Faculty of Food Technology at Latvia University of Agriculture.

\section{Raw material characterisation}

Raw materials for crispbread production were wheat flour, rice flour, wheat bran $(72 \%, 24 \%$ and $4 \%$ respectively) with addition of microwave-vacuum dried by-product powder in different amount $(5 \%$, $10 \%, 15 \%, 20 \%$ ) obtained from local vegetable processors JSC Terrosk and catering company Vairak Saules.

By-product moisture was $80.20 \% \pm 5.50 \%$.

By-products were dried in a microwave - vacuum dryer "MUSON-1" (Russia) according to developed program and by- product weight separetly to receive by-product with moisture content from $3.0 \%$ to $5.5 \%$.

Dried apple and vegetable by-products were separately ground to a powder by a grinder FOSS KNIFITECTM 1095 for 30 seconds each grind. And then they were sieved through a $2 \mathrm{~mm}$ sieve.

For development of crispbreads, as raw materials also 405 type wheat flour (JSC Dobeles dzirnavnieks, moisture $9.86 \%$ ), rice flour obtained from rice grains 
(JSC Valdo, moisture 8.4\%) by grinding, 2365 type wheat bran (JSC Valdo) moisture 5.94\%) were used. Crispbread preparation

Crispbread samples were prepared according to recipes shown in Table 1.

Table 1

Raw material formulation in crispbreads

\begin{tabular}{|c|c|c|c|c|c|}
\hline $\begin{array}{l}\text { Ingredients \% } \\
\text { DW }\end{array}$ & $\begin{array}{l}\overline{0} \\
\dot{\Xi} \\
\dot{U}\end{array}$ & 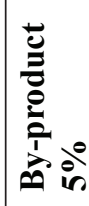 & 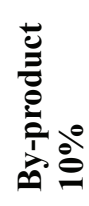 & 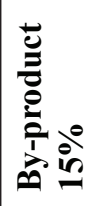 & 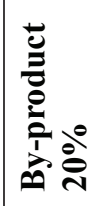 \\
\hline Wheat & 72.0 & 70.0 & 67.5 & 65.0 & 62.5 \\
\hline Rice & 24.0 & 22.0 & 20.0 & 18.0 & 16.0 \\
\hline Wheat bran & 4.0 & 3.0 & 2.5 & 2.0 & 1.5 \\
\hline \begin{tabular}{|l|} 
By-product \\
powder (apple, \\
carrot or \\
pumpkin)
\end{tabular} & - & 5 & 10 & 15 & 20 \\
\hline TOTAL & 100 & 100 & 100 & 100 & 100 \\
\hline
\end{tabular}

The moisture content of raw materials and crispbreads was determined by a standard method LVS EN ISO712:2010A in Memmert equipment, Modell-100-800.

Extrusion process was performed using a laboratory single-screw extruder GÖTTFERT 1 screw Extrusiometer L series (Germany). An extrusion screw (compression ratio 2:1) at a speed of $60-80 \mathrm{rpm}$ and a rectangular die (aperture: $20 \mathrm{~mm}$ wide, $1.0 \mathrm{~mm}$ high, $100 \mathrm{~mm}$ long) were used.

Temperatures for extrusion process were set 78 ${ }^{\circ} \mathrm{C} / 83{ }^{\circ} \mathrm{C} / 98{ }^{\circ} \mathrm{C}$, screw speed $800 \mathrm{rpm}^{-1}$. Obtained extrudates were cooked at $130{ }^{\circ} \mathrm{C}$ for 20 minutes in conventional oven to receive soft and crispy product.

\section{Chemical analysis}

The total phenolic content (TPC) of the extruded product extracts was determined according to the Folin-Ciocalteu method. Extraction was performed by the method described by Paraman (Paraman et al., 2015). $2.5 \mathrm{~mL}$ of Folin- Ciocalteu reagent (diluted 10 times with water) was added to $0.5 \mathrm{~mL}$ of extracted sample. After 3 minutes $2.0 \mathrm{~mL}$ sodium carbonate $\left(\mathrm{Na}_{2} \mathrm{CO}_{3}\right)$ solution $(7.5 \%)$ was added. The resulting solution was mixed and allowed to stand for 30 minutes at $20 \pm 1 \mathrm{C}$ in dark place. Absorption was read at $765 \mathrm{~nm}$ with JENWAY 630 Spectrophotometer. Results were expressed as milligram Gallic acid equivalent per $100 \mathrm{~g}$ of dry weight (mg GAE $100 \mathrm{~g}^{-1}$ DW).

Antioxidant activity of the extruded product extracts was measured on the basis of scavenging activities of the stable 2, 2-diphenyl-1-picrylhydraziyl (DPPH) radical. The radical scavenging activity was expressed as Trolox equivalents (TE) $100 \mathrm{~g}^{-1}$ DW of extruded material.

\section{Statistical anlysis}

All analysis was triplicate and results are presented as a mean value \pm standard deviation (SD). Statistically significant differences between results were calculated at the level of confidence $\alpha=0.05$. In order to find out if the differences in mean values estimated were statistically significant, the one way analysis of variance was applied and analyzed by Microsoft Excel 2010. To determine differences among samples, analysis of variance (ANOVA) and Pearson`s tests were used.

\section{Results and Discussion}

Antioxidants are of interest to both food scientists and health professionals, and there has been a convergence of interest among researchers in these fields as the role of antioxidants in the diet and their impact on human health has come under attention (Mala, Sathiya Mala, \& EKurian, 2016).

\section{Moisture and Total phenolic compounds (TPC)}

Moisture content in samples before extrusion and after extrusion is shown in Figure 1.

TPC content was determined in dried by-product flour and other ingredients for crispbread production (Figure1).

TPC in by- product flour ranged from 132.44 in carrots to $187.79 \mathrm{mg}$ of $\mathrm{GAEg}^{-1} \mathrm{DW}$ in apple byproduct flour. The results reported by Henri were 60-260 mg GAEg-1 DW in apples obtained with different drying methods (Henr1 et al., 2013). Results about dried pumpkin reported by Priecina and Karklina in pumpkin TPC was 672.19 mg GAE 100 $\mathrm{g}^{-1}$ (Priecina \& Karklina, 2014). For carrots some authors show results ranging from 331.00 to 366.00 mg GAE g ${ }^{-1}$.

TPC was determined for both crispbreads before extrusion and for extruded samples (Table $2)$. The TPC of the extruded products varied from $13.90 \pm 1.01$ in control sample to $108.82 \mathrm{mg} \mathrm{GAE} \cdot 100$ $\mathrm{g}^{-1}$ in crispbreads with $20 \%$ addition of pumpkin byproduct. This increase of polyphenol contents after heating might be responsible for the high antioxidant activity of high temperatures during HTST process and addition of different by product flours. The 


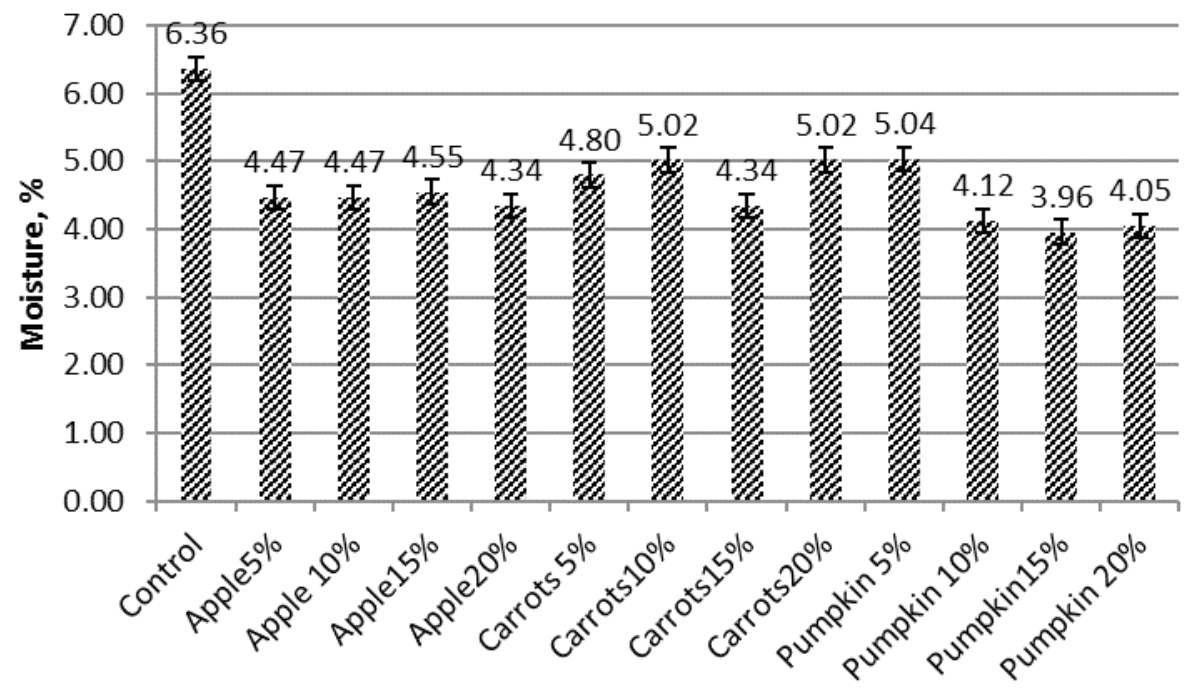

Figure 1. Moisture content in crispbread samples after extrusion.

formation of phenolic compounds might be because of the availability of precursors of phenolic molecules by non-enzymatic interconversion between phenolic molecules. Nayak et al., (2011) reported that the polyphenols in purple potato flour increased from 50 to $160 \mathrm{mg} \mathrm{g}^{-1}$ with an increase in heating temperature. Phenolic compounds are heatliable and can break at the exposure to high temperatures, in samples with carrot BPF (by-product flour) addition. TPC after extrusion decreased in all samples with 5-15\% added BPF except TPC where it increased in the sample with $20 \%$ of carrot BPF addition. Therefore, losses in the TP content of the formulations under extrusion are expected to occur, due to break down of complex polyphenols to other phenolic or nonphenolic compounds, at a consequence of high temperature conditions (Nayak et al., 2011). Another explanation for the higher TPC after heating, for apple and pumpkin BPF addition at least in part is an increased formation of anthocyanins of browning compounds caused by the Maillard reaction at high temperatures. Viscidi and others (2004) reported a significant loss of total phenolics during extrusion of oat cereals. Scientists have reported losses of up to approximately $60 \%$ of phenolic compounds in extruded oat samples, compared to its respective raw sample. Camire reported higher content of soluble phenolics, as ferulic acid equivalents, in Concord grape and raspberry extrudates compared to their control samples (Camire, 2011).

Some studies indicate that levels of phenolic acids, especially ferulic acid and diferulate esters of some whole grain products, including wheat products increase after thermal treatment.

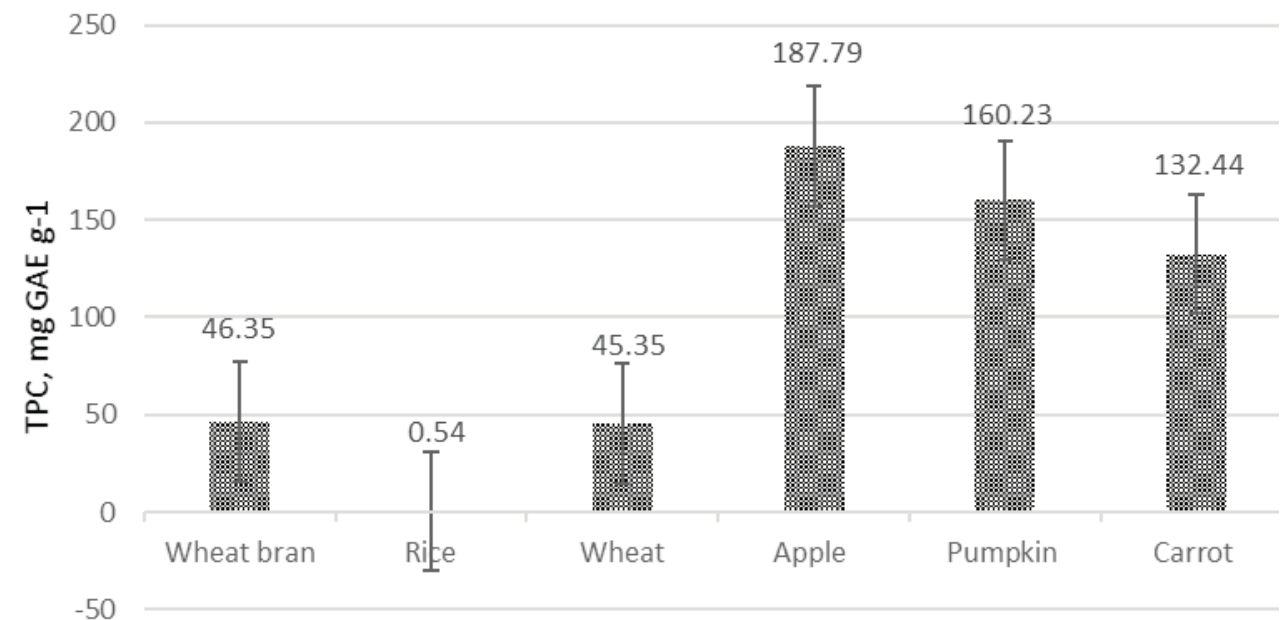

Figure 2. TPC in raw material for crispbreads. 
Total phenolic content in crispbreads before extrusion and after extrusion

\begin{tabular}{|l|c|c|}
\hline \multirow{2}{*}{\multicolumn{1}{|c|}{ Samples }} & \multicolumn{2}{|c|}{ TPC, mg GAE·100 g-1 DW } \\
\cline { 2 - 3 } & $\begin{array}{c}\text { Before } \\
\text { extrusion }\end{array}$ & $\begin{array}{c}\text { After } \\
\text { extrusion }\end{array}$ \\
\hline Control crispbread & $36.06 \pm 1.15$ & $13.90 \pm 1.01$ \\
\hline Apple 5\% & $49.26 \pm 1.57$ & $52.40 \pm 2.14$ \\
\hline Apple 10\% & $51.44 \pm 1.07$ & $77.22 \pm 2.14$ \\
\hline Apple 15\% & $53.83 \pm 0.46$ & $92.74 \pm 3.14$ \\
\hline Apple 20\% & $58.20 \pm 0.25$ & $106.25 \pm 2.08$ \\
\hline Carrots 5\% & $37.75 \pm 2.68$ & $19.70 \pm 1.04$ \\
\hline Carrots 10\% & $45.36 \pm 3.22$ & $34.95 \pm 1.12$ \\
\hline Carrots 15\% & $47.25 \pm 4.25$ & $40.21 \pm 2.25$ \\
\hline Carrots 20\% & $52.61 \pm 3.58$ & $84.73 \pm 3.45$ \\
\hline Pumpkin 5\% & $39.62 \pm 2.68$ & $36.92 \pm 2.87$ \\
\hline Pumpkin 10\% & $44.10 \pm 3.08$ & $58.71 \pm 4.02$ \\
\hline Pumpkin 15\% & $47.89 \pm 2.42$ & $76.75 \pm 4.55$ \\
\hline Pumpkin 20\% & $55.49 \pm 2.68$ & $108.82 \pm 1.04$ \\
\hline
\end{tabular}

Content of phenolic compounds in apple and pumpkin by-product flour indicated the formation of phenolic substances during extrusion and for crispbread samples extrusion led to changes in TPC. The addition of 5, 10 and $15 \%$ of carrot by-product to extrudates decreased TPC during extrusion, except for samples with $20 \%$ carrot byproduct addition increased TPC from 52.61 \pm 3.58 before extrusion to $84.73 \pm 3.45 \mathrm{mg} \mathrm{GAE} \cdot 100 \mathrm{~g}^{-1}$ after extrusion. Degradation of TPC during extrusion also depends upon the nature of raw materials and different composition of phenolic substances such as carrotenoids ( $\beta$-carotene, $\alpha$-carotene, and $\beta$-cryptoxanthin).

\section{DPPH antioxidant activity}

The polarity of plant radical scavenging components is important factor defining extracts antioxidant activity. The antioxidant activity of by products, using DPPH assay, was 5.59 $\pm 0,07 \mathrm{TE} 100 \mathrm{~g}^{-}$ ${ }^{1} \mathrm{DW}$ in carrots and $6.24 \pm 0.05 \mathrm{TE} 100 \mathrm{~g}^{-1} \mathrm{DW} \mathrm{DPPH}$ antiradical activity in apple by- product (Figure 2).

After extrusion antioxidant activity increases and correlates $(\mathrm{r}=0.74)$ with total phenols increasing in samples. Some researchers show a decrease during heat treatment in extrusion while others show an increase or no change (Sojak et al., 2014; Zargar et al., 2014) for both phenols and antioxidant activity. Addition of apple, pumpkin and carrot by-product increased antioxidant activity in samples (Table 3 ).

Table 3

\section{DPPH antioxidant activity}

\begin{tabular}{|l|c|c|}
\hline \multirow{2}{*}{ Samples } & \multicolumn{2}{c|}{ DPPH, TE $\mathbf{1 0 0 g}^{-1} \mathbf{~ D W}$} \\
\cline { 2 - 3 } & $\begin{array}{c}\text { Before } \\
\text { extrusion }\end{array}$ & $\begin{array}{c}\text { After } \\
\text { extrusion }\end{array}$ \\
\hline Control crispbread & $0.35 \pm 0.01$ & $1.07 \pm 0.01$ \\
\hline Apple 5\% & $0.64 \pm 0.02$ & $2.70 \pm 0.01$ \\
\hline Apple 10\% & $0.94 \pm 0.02$ & $3.16 \pm 0.01$ \\
\hline Apple 15\% & $1.24 \pm 0.01$ & $3.44 \pm 0.02$ \\
\hline Apple 20\% & $1.54 \pm 0.03$ & $3.77 \pm 0.02$ \\
\hline Carrots 5\% & $0.61 \pm 0.01$ & $1.59 \pm 0.02$ \\
\hline Carrots 10\% & $0.88 \pm 0.02$ & $1.95 \pm 0.02$ \\
\hline Carrots 15\% & $1.14 \pm 0.02$ & $2.16 \pm 0.03$ \\
\hline Carrots 20\% & $1.42 \pm 0.03$ & $2.52 \pm 0.03$ \\
\hline Pumpkin 5\% & $0.55 \pm 0.01$ & $2.61 \pm 0.01$ \\
\hline Pumpkin 10\% & $0.76 \pm 0.01$ & $2.88 \pm 0.02$ \\
\hline Pumpkin 15\% & $0.96 \pm 0.01$ & $3.74 \pm 0.03$ \\
\hline Pumpkin 20\% & $1.17 \pm 0.02$ & $3.77 \pm 0.02$ \\
\hline
\end{tabular}

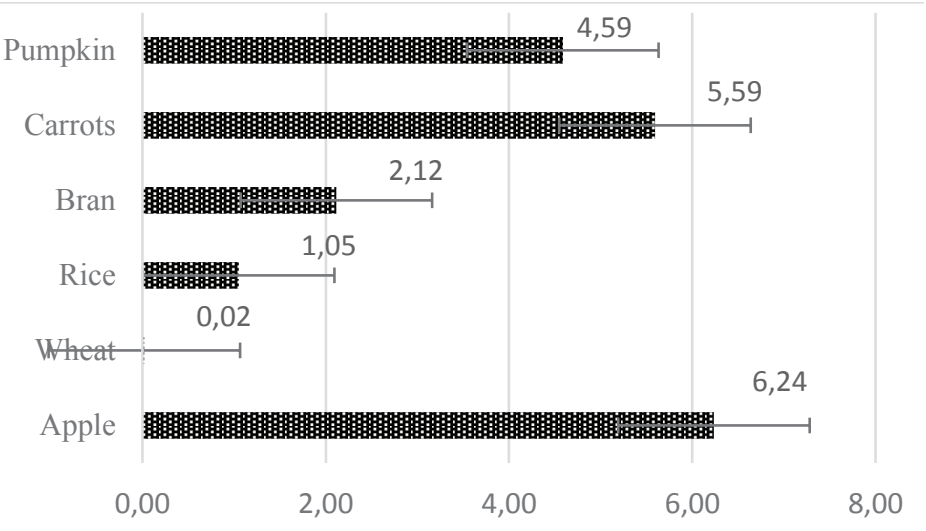

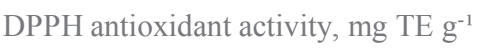

Figure 3. DPPH antioxidant activity in raw material for crispbreads. 
Table 4

Pearson's coefficients between the phenolic compound levels and antioxidant activity before and after extrusion

\begin{tabular}{|l|c|c|c|}
\hline \multicolumn{1}{|c|}{ Between group } & $\begin{array}{c}\text { Samples with } \\
\text { apple BPF }\end{array}$ & $\begin{array}{c}\text { Samples with } \\
\text { carrot BPF }\end{array}$ & $\begin{array}{c}\text { Samples with } \\
\text { pumpkin BPF }\end{array}$ \\
\hline TPC before extrusion / TPC after extrusion & 0.95 & 0.91 & 1.00 \\
\hline TPC before extrusion /DPPH before extrusion & 0.98 & 0.98 & 0.99 \\
\hline TPC after extrusion / DPPH after extrusion & 0.99 & 0.77 & 0.98 \\
\hline DPPH before extrusion / DPPH after extrusion & 0.99 & 0.94 & 0.99 \\
\hline
\end{tabular}

There is doubtful information on the effects of extrusion processes on antioxidant and phenolic properties, and it remains a controversial subject. Reactions such as Maillard reaction (nonenzymatic browning), caramelization, and chemical oxidation of phenols could also contribute to the increase in total phenol content. Thermal processing may also change the ratio between various phenolic compounds (Guine, Raquel de Pinho Ferreira Correia, \& P.M. dos R., 2013). Another study showed a significant reduction in antioxidant activity for $60-68 \%$ and for TPC 46$60 \%$ in extrusion of barley flour (Altan, Mccarthy, \& Maskan, 2008). Behaviour of phenolic compounds present in selected cereals (wheat, rice) during extrusion cooking at high temperatures significantly varied among cereals (Zielinski, Kozlowska, \& Lewczuk, 2001). While Camire (2011) reported no significant change $(P>0.05)$ in the antioxidant activity of the control and cranberry extruded products prepared with corn at substitution level of $1 \%$. Kumar and Sharma investigated the action of different antioxidants and reported a significant decrease in total phenolic content during barley flour extrusion (Kumar et al. 2013; Sharma, Yadav, \& Ritika, 2008).

Correlation between TPC, DPPH antioxidant activity

For all samples the Pearson's coefficients between the phenolic compound levels and antioxidant activity were determined (Table 4).

For all crispbread samples correlation between groups of samples before extrusion and after extrusion was very strong $0.91<\mathrm{r}<0.99$, $(\mathrm{p}<0.05)$. For samples with carrot BPF correlation between TPC after extrusion and DPPH after extrusion was moderate $(\mathrm{r}=0.77)$.

\section{Conclusions}

The stability of total phenolic content (TPC) and antioxidant activity after high temperature and short time (HTST) extrusion cooking of a wheat and ricebased crispbreads with addition of apple and pumpkin by-products increased for all samples. Addition of $20 \%$ apple by product flour increased TPC to $106.25 \pm 2.08 \mathrm{mg} \mathrm{GAE} \cdot 100 \mathrm{~g}^{-1}$ and $20 \%$ of pumpkin by-product flour increased TPC to $108.82 \pm 1.04 \mathrm{mg}$ GAE $100 \mathrm{~g}^{-1}$. The addition of carrot by- products decreased TPC in extruded samples from $37.75 \pm 2.68$ before extrusion to $19.70 \pm 1.04$ after extrusion with 5\% carrot byproduct addition. Though addition of $20 \%$ of carrot by- product increased TPC from $52.61 \pm 3.58$ before extrusion to $84.73 \pm 3.45 \mathrm{mg} \mathrm{GAE} \cdot 100 \mathrm{~g}^{-1}$ after extrusion. Therefore, we have to conclude that the difference of phenolic compounds in by- products can result in such differences.

Our study demonstrated that food products rich in antioxidants can be produced from cereals with addition of apple, carrot and pumpkin by-products using extrusion technology retaining the stability of biologically active substances.

\section{References}

1. Altan, A., Mccarthy, K. L., \& Maskan, M. (2008). Evaluation of snack foods from barley - tomato pomace blends by extrusion processing, 84, 231-242. DOI: 10.1016/j.jfoodeng.2007.05.014.

2. Arscott, S. A., \& Tanumihardjo, S. A. (2010). Carrots of Many Phytochemicals Acting as Functional Food. Comprehensive Reviews in Food Science and Food Safety, 9, 223:239.

3. Aziah, A. A. N., \& Komathi, C. A. (2009). Physicochemical and functional properties of peeled and unpeeled pumpkin flour. Journal of Food Science, 74(7), 328-334. DOI: 10.1111/j.1750-3841.2009.01298.x.

4. Camire, M. (2011). Nutritional Changes during Extrusion Cooking. Advances in Food Extrusion Technology, 87-102. DOI: 10.1201/b11286-5.

5. Dutta, D., Dutta, A., Raychaudhuri, U., \& Chakraborty, R. (2006). Rheological characteristics and thermal degradation kinetics of beta-carotene in pumpkin puree. Journal of Food Engineering, 76(4), 538-546. DOI: 10.1016/j.jfoodeng.2005.05.056. 
6. Elleuch, M., Bedigian, D., Roiseux, O., Besbes, S., Blecker, C., \& Attia, H. (2011). Dietary fibre and fibre-rich by-products of food processing: Characterisation, technological functionality and commercial applications: A review. Food Chemistry, 124(2),411421. DOI: 10.1016/j. foodchem.2010.06.077.

7. Emin, M.A., Mayer-Miebach, E., \& Schuchmann, H. P. (2012). Retention of $\beta$-carotene as a model substance for lipophilic phytochemicals during extrusion cooking. LWT - Food Science and Technology, 48(2), 302-307, DOI: 10.1016/j. lwt.2012.04.004.

8. Eskicioglu, V., Kamiloglu, S., \& Nilufer-erdil, D. (2015). Antioxidant Dietary Fibres: Potential Functional Food Ingredients from Plant Processing By-Products, 2015(6), 487-499., DOI: $10.17221 / 42 / 2015-C J F S$.

9. Figuerola, F., \& Mar, A. (2005). Food Chemistry Fibre concentrates from apple pomace and citrus peel as potential fibre sources for food enrichment, 91, 395-401, DOI: 10.1016/j. foodchem.2004.04.036.

10. Guine, Raquel de Pinho Ferreira Correia, P. M. dos R. (2013). Engineering Aspects of Cereal and Cereal-Based Products, 367. Retrieved August 20, 2017, from https://books.google. com/books?id=3RHSBQAAQBAJ\&pgis $=1$.

11. Haminiuk, C. W. I., Maciel, G. M., Plataoviedo, M. S. V, \& Peralta, R. M. (2012). Invited review Phenolic compounds in fruits an overview, 2023-2044. DOI: 10.1111/j.13652621.2012.03067.x.

12. Henrı, M., Almonacid, S., Lutz, M., Simpson, R., \& Valdenegro, M. (2013). Comparison of three drying processes to obtain an apple peel food ingredient ' $\mathrm{n}$ de tres procesos de secado para obtener un ingrediente alimentario de ca' scara de Comparacio manzana, 11(2), 127-135.

13. Huber, G. (2001). Snack Foods from Cooking Extruders. Snack Foods Processing. DOI: 10.1201/9781420012545.ch12.

14. Kumar, K., Jindal, N., Sharma, S., \& Nanda, V. (2013). Physico-chemical and antioxidant properties of extrudates developed from honey and barley. International Journal of Food Science and Technology, 48(8), 1750-1761. DOI: $10.1111 /$ ijfs. 12147 .

15. Mala, S., Sathiya Mala, K., \& EKurian, A. (2016). Nutritional Composition and Antioxidant Activity of Pumpkin Wastes. Ijpcbs 2016, 6(3), 336-344.

16. Nayak, B., Berrios, J. D. J., Powers, J. R., \& Tang, J. (2011). Effect of Extrusion on the Antioxidant
Capacity and Color Attributes of Expanded Extrudates Prepared from Purple Potato and Yellow Pea Flour Mixes, 76(6), 874-884. DOI: 10.1111/j.1750-3841.2011.02279.x.

17. Olfe, K. E. W., Ianzhong, X. W. U., \& Iu, R. U. I. H. A. I. L. (2003). Antioxidant Activity of Apple Peels, 609-614.

18. Paraman, I., Sharif, M. K., Supriyadi, S., \& Rizvi, S. S. H. (2015). Food and Bioproducts Processing Agro-food industry byproducts into value-added extruded foods. Food and Bioproducts Processing, 96, 78-85. DOI: 10.1016/j.fbp.2015.07.003.

19. Priecina, L., \& Karklina, D. (2014). Natural Antioxidant Changes in Fresh and Dried Spices and Vegetables, 3001(5), 492-496.

20. Provesi, J. G., Dias, C. O., \& Amante, E. R. (2011). Changes in carotenoids during processing and storage of pumpkin puree, 128, 195-202. DOI: 10.1016/j.foodchem.2011.03.027.

21. Rakcejeva, T., Galoburda, R., Cude, L., \& Strautniece, E. (2011). Use of dried pumpkins in wheat bread production. Italian Oral Surgery, 1, 441-447. DOI: 10.1016/j.profoo.2011.09.068.

22. Rizui, S. S. H. (2015). Food and Bioproducts Processing Agro-food industry byproducts into value-added extruded foods ( $\mathrm{g}$ ) C r o s s a r k, 6 .

23. Sarawong, C., Schoenlechner, R., Sekiguchi, K., Berghofer, E., \& Ng, P. K. W. (2014). Effect of extrusion cooking on the physicochemical properties, resistant starch, phenolic content and antioxidant capacities of green banana flour. Food Chemistry, 143. DOI: 10.1016/j. foodchem.2013.07.081.

24. Sharma, A., Yadav, B. S., \& Ritika. (2008). Resistant Starch: Physiological Roles and Food Applications. Food Reviews International, 24(2), 193-234. DOI: 10.1080/87559120801926237.

25. Sojak, M. J., Jaros, M., \& Głowacki, S. (2014). Analysis of Giant Pumpkin (Cucurbita maxima) Quality Parameters in Various Technologies of Convective Drying After Long-Term Storage. Drying Technology, 32 (January 2015), 106-116. DOI: $10.1080 / 07373937.2013 .816854$.

26. Waramboi, J. G., Gidley, M. J., \& Sopade, P. A. (2013). Carotenoid contents of extruded and nonextruded sweetpotato flours from Papua New $\overline{\text { Guinea and Australia. Food Chemistry, 14 }} \overline{1 \text { (3), }}$ 1740-6, DOI: 10.1016/j.foodchem.2013.04.070.

27. Zargar, F. A., Kumar, S., Bhat, Z. F., \& Kumar, P. (2014). Effect of pumpkin on the quality characteristics and storage quality of aerobically packaged chicken sausages. SpringerPlus, 3(39), DOI: 10.1186/2193-1801-3-39. 
Total Content of Phenolics and Antioxidant Activity

28. Zielinski, H., Kozlowska, H. \& Lewczuk, B. (2001). Bioactive compounds in the cereal

Innovative Food Science and Emerging grains before and after hydrothermal processing.

Technology, 2, 159-169.

\section{Acknowledgment}

Research has been supported by the National research programme "Agricultural Resources for Sustainable Production of Qualitative and Healthy Foods in Latvia" (AgroBioRes) (2014 2017), project No. 4 "Sustainable use of local agricultural resources for qualitative and healthy food product development” (FOOD). 